\title{
Retraction Note to: Surgical management of intractable spasticity
}

\author{
Mohamed I. Barakat ${ }^{1} \cdot$ Waleed Elhady $^{1} \cdot$ Mohamed Gouda $^{1} \cdot$ Mahmoud Taha $^{1} \cdot$ \\ Ibrahim Metwaly ${ }^{1}$
}

Published online: 19 April 2016

(c) Springer-Verlag Berlin Heidelberg 2016

\section{Retraction to: Eur Spine J (2016) 25:928-935 DOI 10.1007/s00586-015-4326-y}

This article, 'Surgical management of intractable spasticity', Mohamed I. Barakat, Waleed Elhady, Mohamed Gouda, Mahmoud Taha and Ibrahim Metwaly published in European Spine Journal, March 2016, Vol. 25, Issue 3, pp 928-935, First online: 14 December 2015, DOI 10. 1007/s00586-015-4326-y, has been retracted at the request of the Editor-in-Chief because this article has considerable overlap with the paper published in the Zagazeg University Journal, Egypt, ISSN 1110-1431, in 10-9-2012. Therefore it does not represent entirely original material and has to be withdrawn. The authors have agreed to retract the article, recognizing that it constitutes duplicate publication. In addition Mohamed Gouda asked to remove his name from the paper as a co-author because he had no direct or indirect relations with this paper.

The online version of the original article can be found under doi:10.1007/s00586-015-4326-y.

Mohamed I. Barakat

mohamedebarakat@hotmail.com

Waleed Elhady

waleedelhadi@hotmail.com

Mohamed Gouda

drmohamedammar@yahoo.com

Mahmoud Taha

mahmoudlotfy72@yahoo.com

Ibrahim Metwaly

Ibrahimmetwally@hotmail.com

1 Neurosurgery Department, Faculty of Medicine, Zagazig

University, Zagazig, Egypt 